\title{
Carbon emissions embodied in demand-supply chains in China
}

\author{
Hongguang Liu ${ }^{\mathrm{a}, *}$, Weidong Liu ${ }^{\mathrm{b}}$, Xiaomei Fan ${ }^{\mathrm{c}}$, Wei Zou ${ }^{\mathrm{a}}$ \\ a College of Public Administration, Nanjing Agricultural University, Nanjing 210095, China \\ ${ }^{\mathrm{b}}$ Institute of Geographic Sciences and Natural Resources Research, Chinese Academy of Sciences, Beijing 100101, China \\ c School of Remote Sensing, Nanjing University of Information Science and Technology, Nanjing 210044, China
}

\section{A R T I C L E I N F O}

\section{Article history:}

Received 27 July 2014

Received in revised form 4 June 2015

Accepted 8 June 2015

Available online 19 June 2015

\section{JEL classifications:}

C67

F18

Q56

Q57

R11

R15

\section{Keywords:}

Embodied emissions

Input-output

Demand-supply chain

China

\begin{abstract}
A B S T R A C T
Using the multi-regional input-output model (MRIO), the paper distinguishes the carbon emissions embodied in commodities for domestic final consumption (CBEs, consumption-based emissions) and those for export (EBEs, export-based emissions), and then calculates carbon emissions embodied in the demand-supply chains for consumption and export based on technical coefficients matrix of the MRIO for one country. Taking China as an example, we provide a dynamic analysis of CBEs, EBEs, and carbon emissions embodied in consumption and export demand-supply chains at the sub-national level based on the MRIO tables for 1997 and 2007. The results show that, in China, the transferred carbon emissions embodied in demand-supply chains driven by consumption and export both showed rapid growth during 1997-2007. And the net transferred carbon emissions embodied in the demand-supply chains showed an increasing trend as well. Less developed regions with abundant fossil fuels tend to net flow out carbon emissions.
\end{abstract}

(c) 2015 Elsevier B.V. All rights reserved.

\section{Introduction}

The United Nations Framework Convention on Climate Change (UNFCCC) requires parties to submit annual National Emission Inventories to benchmark progress towards the goals of the UNFCCC (Peters, 2008). The UNFCCC system boundary include all greenhouse gas emissions and removals taking place within national (including administered) territories and offshore areas over which the country has jurisdiction, so it is named production-based emissions accounting (PBE). In the perspective of PBE, the emissions associated with exports are included but those associated with imports are excluded from the national account. Along with the globalization and expansion of international trade, industries including energy intensive industries are gradually transferring from developed countries (almost the Annex I countries that have a responsibility to reduce carbon emissions in UNFCCC) to developing and less developing countries (almost the non-annex I countries without stringent climate change policies in UFCCC). For their part, the non-Annex 1 countries accept this industry transfer from developed countries given the economic benefit it brings them; however, the production technology of most developing

\footnotetext{
* Corresponding author at: College of Public Administration, Nanjing Agricultural University, No. 1 WeiGang Street, XuanWu District, Nanjing, 210095 China. Tel./fax: + 86 2584395700 .

E-mail address: liuhg@njau.edu.cn (H. Liu).
}

countries is generally lower than that of developed countries, meaning that the emission of one unit output is relatively higher, and comes in addition to the emissions caused by forest destruction as the consequence of industrialization in developing countries. Combined, these effects may make global emissions higher. This phenomenon is called "carbon leakage", one main critique of PBE (Peters and Hertwich, 2008; Bednar-Friedl et al., 2012).

Aimed to solve problem of "carbon leakage", many scholars have proposed the consumption-based emissions ( $\mathrm{CBE}$ ) accounting system and tried to assess the emissions embodied in global trade (Barrett et al., 2013; Davis and Caldeira, 2010; Munksgaard and Pedersen, 2001; Wilting and Vringer, 2007; Yang et al., 2014; Zsófia, 2013). Research on this topic could be roughly divided into two categories. The first is a separate study on carbon emissions embodied in the trade either internally within a specific-country or the trade between two countries (Lenzen, 1998; Sánchez-Chóliz and Duarte, 2004; Pan et al., 2008; Lin and Sun, 2010; Li and Hewitt, 2008; Yu and Wang, 2010; Xu et al., 2009; Dong et al., 2010; Du et al., 2011; Machado et al., 2001; Mäenpää and Siikavirta, 2007; McGregor et al., 2008; Rhee and Chung, 2006). The second is a comprehensive study on carbon emissions embodied in global trade between major countries or regions in the world (Ahmad and Wyckoff, 2003; Chen and Chen, 2011; Davis et al., 2011; Lenzen et al., 2004; Munksgaard et al., 2005; Peters et al., 2011). Authoritative research shows that the carbon emissions 
embodied in global trade have increased rapidly, with China currently being the world's largest carbon-export country (Peters et al., 2011).

In light of these findings, many other scholars began to study the issue of carbon emissions in China (Chen and Zhang, 2010; Dietzenbacher et al., 2012; Guan et al., 2009; Liu et al., 2015; Peters et al., 2007). Some scholars have estimated the embodied carbon emissions of China's foreign trade (Guo et al., 2012; Lin and Sun, 2010; Weitzel and Ma, 2014; Zhang, 2012, 2013). Their findings show that, in addition to the increase in China's own consumption level and accelerated investment in fixed assets, rapidly expanding export is the other major reason why China has seen an increase in its carbon emissions. Other studies have calculated the embodied carbon emissions in the trade between China and specific countries such as the UK, US, Japan, etc. (Dong et al., 2010; Du et al., 2011; Li and Hewitt, 2008; Xu et al., 2009; Yu and Wang, 2010). With the gradual increase in pressure on China to reduce its carbon emissions, the government has promised to reduce carbon emissions per unit of GDP by $40-45 \%$ between 2005 and 2020, and has incorporated these carbon reduction targets into the assessment indicators of the provincial administrative regions in economic and social development. However, China is a big country, with big gaps between regions in terms of their resource endowment, economic level, industrial structure and level of carbon emissions (Afton et al., 2011; Feng et al., 2009). Furthermore, it has been argued that the implementation of the regional emission reduction policy may exacerbate the inter-regional carbon leakage problem as there are fewer barriers to trade between the regions than to trade between countries (Afton et al., 2011; Feng et al., 2009; Meng et al., 2011). To engage with this problem, several studies have been conducted that have found a large-scale carbon leakage problem in different Chinese regions. Guo et al. (2012) and Shi et al. (2012) analyzed carbon emissions embodied in provincial final demand and inter-provincial carbon transfer within China by employing a multi-regional input-output (MRIO) table of 2002 for China. Meng et al. (2013) and Zhang et al. (2014) presented a dynamic analysis on the interregional transfer of $\mathrm{CO}_{2}$ emissions of China and found that its $\mathrm{CO}_{2}$ emissions embodied in interprovincial trade sharply increased in 2002-2007. Feng et al. (2013) calculated $\mathrm{CO}_{2}$ emissions associated with consumption in each of the 30 Chinese sub-regions as well as emissions embodied in products traded between these sub-regions and the rest of the world on the basis of the MRIO table for 2007 in China. Su et al. (2010, 2013), Su and Ang (2011, 2014) also accounted for the consumption-based emissions of China, and they also depth analyzed the differentia of the results of models with different aggregations and assumptions.

Two general approaches to multi-region emission studies are the emissions embodied in the bilateral trade (EEBT) approach, as in Guo et al. (2012) and Zhang et al. (2014), and the MRIO approach, as in Meng et al. (2013) and Feng et al. (2013). The major differences between the two lie in the treatment of the feedback effect (Peters, 2008). Su and Ang (2011) indicated that the differences between EEBT and MRIO have been reported in some studies, but none has looked into the feedback mechanism of embodied emissions in detail. They showed that the approach using the competitive imports assumption gives estimates larger than those obtained using the non-competitive import assumption in China (Su and Ang, 2013), and they subsequently presented a hybrid EEBT model to comprehensively investigate the regional emission embodiments of China (Su and Ang, 2014).

Most previous studies apart from Feng et al. (2013) are primarily concerned with carbon emissions embodied in the commodities and the demand-supply chains for whole final use in China. Feng et al. (2013) studied emissions embodied in products traded within China that are triggered by subdivisions of final use (household consumption, capital formation, and international exports) for 2007, but their investigation lacked a dynamic analysis. In the current paper, we follow Feng et al. (2013) and conduct a dynamic analysis (1997-2007) on emissions embodied in inter-regional demand-supply chains caused by different components of final use within China, with the aim of contributing useful commentary on Chinese regional policies on carbon emissions reduction. In this study, regional final use in China is split into final consumption and export, and then consumption-based emissions (CBEs) and export-based emissions (EBEs) are used to explicitly distinguish the eventual use of the emissions in different regions. In addition, the models used to estimate CBEs and EBEs are clearly written by breaking down the calculation procedure of the production-based emissions, and a comparison among results from different studies (including this study) is also given.

The following section will show how we used the MRIO model in order to establish the methodology for this study. The paper will then account for the data sources, and provide the results with analysis and comparison with others. Conclusions and policy recommendations will be promoted at last.

\section{Methods}

Multi-region input-output (MRIO) tables and their applications have aroused substantial interest in the forefront of environmental policy debates. Many previous studies such as Meng et al. (2013), Feng et al. (2013), and Su and Ang (2014) have applied MRIO to estimate $\mathrm{CO}_{2}$ emissions embodied in regional trade in China. Similar with others, we treat MRIO model to adapt our study. Table 1 demonstrates our use of the MRIO model, where a country has $n$ sub-national regions.

Where $x_{d}^{r s}$ refers to domestic intermediate input from region $r$ to produce output in region $s ; y_{d}^{r s}$ is the domestic consumption demand of region $\mathrm{s}$ for region r's products. $e_{d}^{r}$ stands for exports in region $\mathrm{r}$, excluding entrepot trade; $x_{m}^{s}$ signifies imports for intermediate inputs in region $s$. $y_{m}^{s}$ is imported final consumption in region $s ; e_{m}$ refers entrepot trade; $x^{r}$ is the total output in region $r . v^{s}$ refers to the added value in region $s$, and $x^{s}$ is the total input in region $s$.

\subsection{Direct carbon emissions of industries (PBEs)}

The concept of PBE accounting, as used under the Kyoto Protocol, is a straightforward approach to account for carbon emissions. It is characterized by clear system boundaries and good data availability. In this study, we suppose the PBEs of the country to be $C_{P R O}$, and the PBE of region $r$ to be $c_{\text {pro }}^{r}$. The PBE of region $r$ divided by the total output in region $r$ could obtain the quantity of direct carbon emissions per unit of output, namely, the direct carbon emissions factor of region $r$, as the following formula demonstrates:

$f^{r}=c_{p r o}^{r} / x^{r}$

\subsection{Carbon emissions embodied in the demand-supply chains: CBEs and} EBES

From horizontal angles in Table 1, we obtain

$X=\left(I-A_{d}\right)^{-1} \cdot\left(Y_{d}+E_{d}\right)$

where $A_{d}$ expresses the domestic inter-industry requirements (the named domestic technical coefficient matrix), $Y_{d}$ is the final use matrix for all regions, and $E_{d}$ is the export matrix. For convenience, we denote matrix $\left(I-A_{d}\right)^{-1}$ (generally named Leontief inverse matrix or cumulative coefficient matrix) by $B$, and obtain the following:

$X=B \cdot\left(Y_{d}+E_{d}\right)$.

By multiplying both sides of formula (3) by $F$, the national gross emissions can be expressed as follows:

$C_{\text {pro }}=F \cdot X=F \cdot B \cdot\left(Y_{d}+E_{d}\right)$ 
Table 1

Multi-regional input-output table of a country with $\mathrm{n}$ regions.

\begin{tabular}{|c|c|c|c|c|c|c|}
\hline & & & \multirow{2}{*}{$\frac{\text { Intermediate use }}{\text { Region } 1 \ldots \text { region } n}$} & \multicolumn{2}{|l|}{ Final use } & \multirow[t]{2}{*}{ Total output } \\
\hline & & & & Region 1 ...region $n$ & Export & \\
\hline Intermediate input & Domestic & $\begin{array}{l}\text { Region } 1 \\
\ldots \\
\text { Region } n\end{array}$ & $x_{d}^{r s}$ & $y_{d}^{r s}$ & $e_{d}^{r}$ & $x^{r}$ \\
\hline $\begin{array}{l}\text { Added value } \\
\text { Total input }\end{array}$ & Import & & $\begin{array}{l}x_{m}^{s} \\
v^{s} \\
x^{s}\end{array}$ & $y_{m}^{s}$ & $e_{m}$ & \\
\hline
\end{tabular}

where $F$ is the row matrix of $f^{r}$, Specifically:

$F \cdot X=\left(f^{1} \cdots f^{r} \cdots f^{n}\right) \cdot\left(\begin{array}{cccc}b^{11} & b^{12} & \cdots & b^{1 n} \\ b^{21} & b^{22} & \cdots & b^{2 n} \\ \vdots & \vdots & \ddots & \vdots \\ b^{n 1} & b^{n 2} & \cdots & b^{n n}\end{array}\right) \cdot\left\{\left(\begin{array}{ccc}y_{d}^{11} & \cdots & y_{d}^{1 n} \\ y_{d}^{21} & \cdots & y_{d}^{2 n} \\ \vdots & \ddots & \vdots \\ y_{d}^{n 1} & \cdots & y_{d}^{n n}\end{array}\right)+\left[\begin{array}{c}e^{1} \\ e^{2} \\ \vdots \\ e^{n}\end{array}\right]\right\}$

where $b^{r s}$ is block matrix in $\left(I-A_{d}\right)^{-1}$, it means the cumulative output produced in region $r$ demanded by the final use in region $s$. Assuming there are no differences in the production requirements in the model for producing one unit of export or one unit of consumption ${ }^{1}$, by breaking down formula (5), the emissions in $r$ caused by final use in all regions (including region $r$ ) can be expressed as follows:

$C_{\text {pro }}^{r}=f^{r} \cdot \sum_{j} \sum_{i} b^{r i} y_{d}^{i j}+f^{r} \cdot \sum_{k} b^{r k} e^{k}=C_{\text {pro.con }}^{r}+C_{\text {pro.ex }}^{r}$

where $C_{\text {pro.con }}^{r}$ denotes region $r$ 's direct emissions for national consumption, and $C_{\text {pro.ex }}^{r}$ stands for region $r$ 's direct emissions for national export. By further breaking down formula (6), the emissions in $r$ caused by final use in $s$-in other words, the emission transfers from $r$ to $s$ caused by consumption in $s$-could be extracted as:

$c_{f i n}^{r s}=f^{r} * \sum_{i} b^{r i} y^{i s}+f^{r} * b^{r s} e^{s}=c_{c o n}^{r s}+c_{e x}^{r s}$.

The first part of the right side in formula (7) refers to the emissions in region $r$ caused by final consumption in region $s$, in other words, the transfer emissions from $r$ to $s$ caused by consumption in $s$. The second part expresses the emissions in region $r$ caused by exports of region $s$, in other words, the transfer emissions from $r$ to $s$ caused by export in $s$. From this, the CBEs (domestic part, similarly hereinafter) in region $s$ can be obtained as follows:

$c_{c o n}^{s}=\sum_{r} c_{c o n}^{r s}$

It should be noted that the CBEs of region s expressed in Eq. (8) cover only domestic part as the emissions embodied in international imports for domestic consumption are not the focus of this study.

And the EBEs in region $s$ could be written as:

$c_{e x}^{s}=\sum_{r} c_{e x}^{r s}$.

We must notice that, the aim of the promotion of EBE is not exactly similar to CBE. A clear reason exists behind providing CBE (where are the consumers "responsible" for the emissions). For EBE, emissions are

\footnotetext{
1 Some recent papers (Dietzenbacher et al., 2012; Su et al., 2013; Weitzel and Ma, 2014) highlight the importance of export processing for Chinese exports. EBE could thus be overstated if the same production structure is assumed for consumption and export goods.
}

attributed to regions where export activity take place, but these regions are "not responsible" for these emissions. EBE is facilitated to reveal the location of the emissions to support national export, and if the export structure adjusts, then the emissions of a certain region would be affected by demand-supply chains.

Given the arbitrary choice of $r$ and $s$, the emissions in $s$ caused by the final use of $r$ could also be written symmetrically:

$c_{f i n}^{s r}=f^{s} * \sum_{i} b^{s i} y^{i r}+f^{s} * b^{s r} e^{r}=c_{c o n}^{s r}+c_{e x}^{s r}$.

And the net carbon embodied in the demand-supply chain driven by consumption (CEDSC for short, similar with internal trade balance of embodied emissions in other studies such as Su and Ang, 2014) from $r$ to $s$ could be calculated by:

$n c_{c o n}^{r s}=c_{c o n}^{r s}-c_{c o n}^{s r}$

Similarly, the net carbon embodied in the demand-supply chain driven by export (CEDSE for short) from $r$ to $s$ is:

$n c_{e x}^{r s}=c_{e x}^{r s}-c_{e x}^{s r}$

\section{Data sources}

The main data sources used in this study were the 1997 and 2007 Chinese multiregional input output tables (CMRIO) and the database of Chinese provincial energy use and carbon emissions. China does not officially publish a multi-regional input-output model regularly. Therefore, many organizations have compiled CMRIOs for research. Previous studies also applied different CMRIO data sources, such as the data source of Su and Ang (2010), which is the IDE 2003 containing 30 sectors and 8 regions, and that of Zhang et al. (2014), which is the CMRIOs from the Development Research Center of the State Council of China, to analyze the aggregation of 12 sectors and 30 regions. Considering the data available and the comparison, we use the 1997 CMRIO (with 17 sectors and 8 regions) compiled by the China State Information Center in 2005 (State Information Center of China, 2005) and the 2007 CMRIO (with 30 sectors and 30 regions) compiled and published by the National Statistics Bureau (Liu et al., 2012) in our study. Both CMRIOs are available publicly and compiled by the best-known gravity model of Leontief and Strout (1963) based on the known trade matrix of dominant/representative commodities. Nevertheless an augmented gravity model that accommodates the spatial dependences of the dependent variable is used for the 2007 CMRIO table (for more information, see Liu et al., 2012 and SI in Feng et al., 2013). The 2007 CMRIO also has a more specific sector and regional classification (30 sectors and 30 regions) compared with the 8 regions and 17 sectors in the 1997 CMRIO. For comparison, we aggregate the 2007 CMRIO to an $8 \times 17$ classification. Eight sub-national main regions, as shown in 


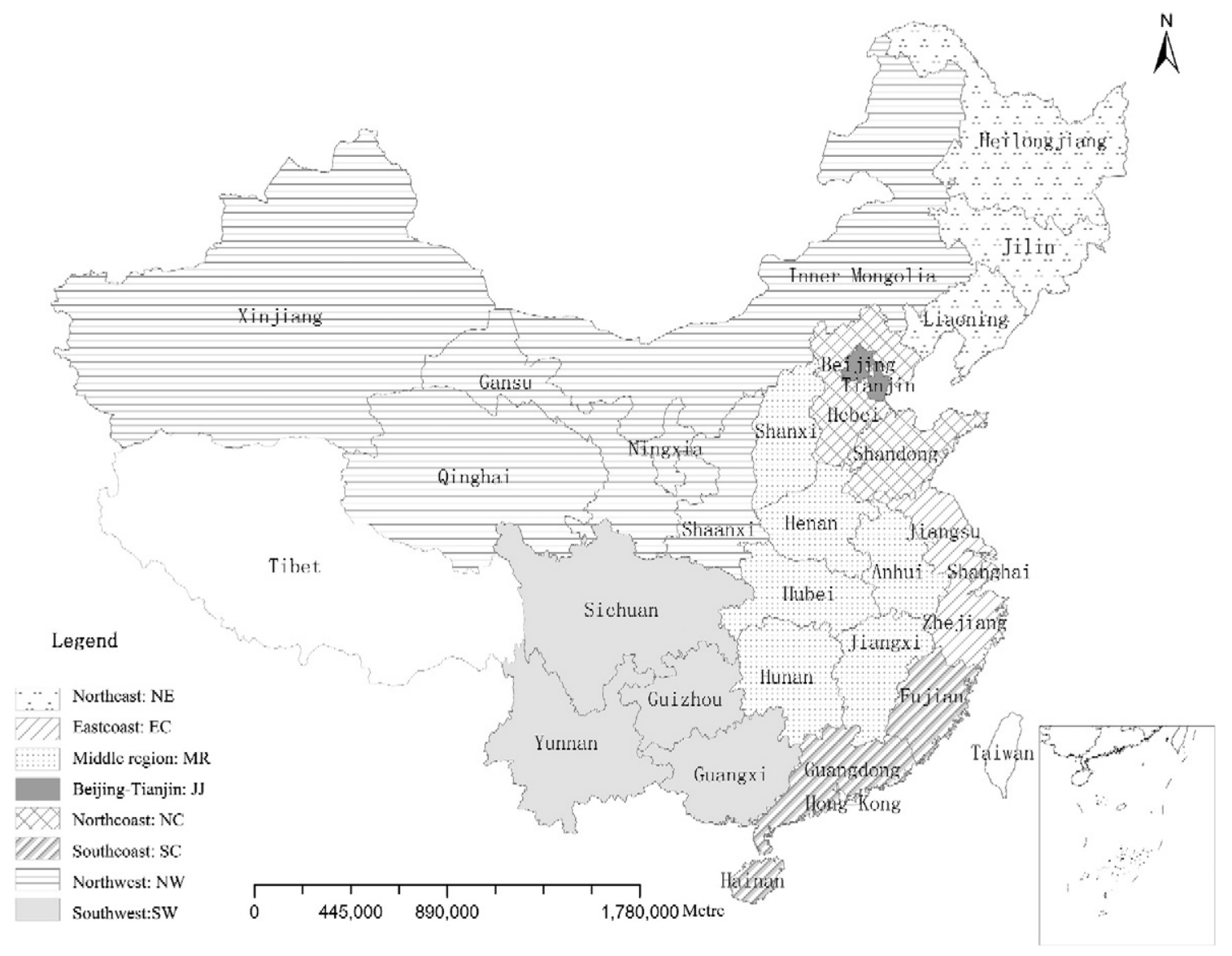

Fig. 1. Eight sub-regions of China. Note: Tibet, Taiwan, Hong Kong and Macau are not included in the research scope of this paper.

Fig. 1, were artificially divided within China except Tibet, Hong Kong, Macau and Taiwan: Northeast (NE, including Heilongjiang, Jilin, Liaoning), Beijing-Tianjin (JJ, Beijing, Tianjin), North Coast (NC, Hebei, Shandong), East Coast (EC, Shanghai, Zhejiang, Jiangsu), Middle region (MR, Henan, Shanxi, Anhui, Hunan, Hubei, Jiangxi), South Coast (SC, Guangdong, Fujian, Hainan), Northwest (NW, Inner Mongolia, Shaanxi, Gansu, Ningxia, Qinghai, Xinjiang), and Southwest (Sichuan, Chongqing, Yunnan, Guizhou, Guangxi). Sectoral classification (17 sectors) is compared with the Chinese standard industrial classification (SIC) of National Economy (GB/T 4754-2002) in Table A1.

The environment data is calculated from the combustion of fuels and industrial processes using the Intergovernmental Panel on Climate Change reference approach (IPCC, 2006). In this study, $\mathrm{CO}_{2}$ emissions from burning fossil fuel and from cement production are included. To calculate carbon emissions, 18 types of combustion of fuels (namely raw coal, cleaned coal, other washed coal, briquettes, coke, coke oven gas, other gas, other coking products, crude oil, gasoline, kerosene, diesel oil, fuel oil, liquid petroleum gas, refinery gas, other petroleum products, natural gas and other energy) and industrial processes were considered in this study. Generally, provincial fuel data and cement output for detailed sectors (generally 44 sectors) could be collected from the China Energy Statistical Yearbooks, and China Provincial Statistical Yearbooks of the target years. However, several provinces, such as Hebei, Heilongjiang, Xinjiang, have no energy consumption by detailed sector. Thus, information about energy consumption in the China Provincial Economic Census by sector is used in estimating energy consumption by sector of the target years. When the values of energy consumption in the China Energy Statistical Yearbooks and the China Provincial Statistical Yearbooks are inconsistent, the value in the former shall prevail. The average low calorific values contained in the appendix of these China Energy Statistical Yearbooks were adopted, complemented by the IPCC 2006 Guidelines (IPCC, 2006) in case the values of any type of energy were unavailable in the China Energy Statistical sources. The potential carbon emission factors by energy use were taken as, by default, the values in IPCC 2006 Guidelines (IPCC, 2006). Generally, the oxidation rate was valued at 1 ; however, considering the efficiency of energy use in China and also according to other studies (Fan et al., 2007), the oxidation rates by the different types of energy were taken as varying between 0.98 and 0.995 . In addition, the energy use and $\mathrm{CO}_{2}$ emissions data for 44 sectors and 30 provinces are aggregated to match the CMRIO classification.

\section{Results}

\subsection{PBEs and regional economic development}

According to the regional total amount of direct carbon emissions (PBE), GDP, and the total output from 1997 and 2007 (at 1997 constant price, ${ }^{2}$ similar hereafter), the regional direct carbon emission factors and per capita GDP could be obtained. These results are shown in Table 2.

From these results, it is evident that, firstly, China's direct carbon emissions mainly came from central and coastal areas, while the Northwest was the fastest growing emissions region. From the PBE results, it can be deduced that the Middle Region, North Coastal, East Coastal and Northeast regions all showed high figures for PBE in 1997

\footnotetext{
2 The 1997 constant price of 2007 is calculated based on the growth rates of real GDP in 1997-2007.
} 
Table 2

Regional carbon emissions and economic development in China.

\begin{tabular}{|c|c|c|c|c|c|c|c|c|c|c|}
\hline & \multirow{2}{*}{\multicolumn{2}{|c|}{$\begin{array}{l}\text { PBE } \\
\text { MtC }\end{array}$}} & \multirow{2}{*}{\multicolumn{2}{|c|}{$\begin{array}{l}\text { Total output } \\
10^{9} \mathrm{CNY}\end{array}$}} & \multirow{2}{*}{\multicolumn{2}{|c|}{$\begin{array}{l}\text { Direct emissions } \\
\text { factor } \\
\mathrm{tC} / 10^{6} \mathrm{CNY}\end{array}$}} & \multirow{2}{*}{\multicolumn{2}{|c|}{$\begin{array}{l}\text { GDP } \\
10^{9} \mathrm{CNY} \\
\end{array}$}} & \multirow{2}{*}{\multicolumn{2}{|c|}{$\begin{array}{l}\text { GDP per capita } \\
10^{3} \mathrm{CNY} \\
\end{array}$}} \\
\hline & & & & & & & & & & \\
\hline & 1997 & 2007 & 1997 & 2007 & 1997 & 2007 & 1997 & 2007 & 1997 & 2007 \\
\hline $\mathrm{NE}$ & 134.09 & 187.14 & 1947 & 5406 & 68.86 & 34.62 & 765 & 2081 & 7.27 & 19.17 \\
\hline JJ & 38.76 & 52.31 & 942 & 3836 & 41.15 & 13.64 & 305 & 1282 & 13.91 & 46.66 \\
\hline NC & 116.80 & 272.83 & 2849 & 10762 & 40.99 & 25.35 & 1060 & 3532 & 6.93 & 21.66 \\
\hline EC & 113.68 & 245.20 & 4625 & 17029 & 24.58 & 14.40 & 1468 & 5048 & 11.26 & 34.71 \\
\hline SC & 72.84 & 136.19 & 2976 & 11204 & 24.48 & 12.16 & 1073 & 3699 & 9.68 & 26.66 \\
\hline MR & 185.97 & 364.36 & 3498 & 11876 & 53.17 & 30.68 & 1639 & 4633 & 4.68 & 13.13 \\
\hline NW & 81.39 & 199.73 & 1122 & 4060 & 72.51 & 49.20 & 467 & 1732 & 4.19 & 14.40 \\
\hline SW & 95.99 & 168.89 & 2024 & 6042 & 47.42 & 27.95 & 920 & 2529 & 3.82 & 10.42 \\
\hline Nation & 839.52 & 1626.65 & 19984 & 70214 & 42.01 & 23.17 & 7696 & 24537 & 6.29 & 18.89 \\
\hline Coefficient of variation & 0.421 & 0.460 & 0.495 & 0.533 & 0.384 & 0.486 & 0.474 & 0.448 & 0.471 & 0.526 \\
\hline
\end{tabular}

Note: MtC, million metric ton of carbon; CNY, Chinese yuan. Source: author's own calculation. Data in this table are calculated at 1997 constant prices.

and 2007. By comparing the regional growth rates of PBE during 19972007, excluding Beijing-Tianjin and the Northeast regions, it can be seen that all other regions exhibited high growth rates (>75\%), with the Northwest being the fastest growing (145.4\%), followed by the North Coast (133.6\%) and the East Coast (115.7\%) areas. Secondly, it can be seen from these results that the regional direct carbon emissions factor is inversely proportional to regional economic development, which indicates that developed regions such as Beijing-Tianjin and Southeast Coastal areas generally have lower carbon emission factors. Conversely, developing regions such as the Northeast and Midwest have higher carbon emission factors.

\subsection{CBEs, EBEs and regional difference}

According to formula (6), one region's carbon emissions could be divided into two parts: carbon emissions caused by final use of the nation (hereafter including fixed capital formation), expressed by the first part of the right side of Eq. (6),and labeled as PBEs (consumption) and carbon emissions induced by the export of all regions, namely, the second part of the right side of Eq. (6), labeled PBEs (export).The CEBs and EBEs could be obtained by formulas (8) and (9). Per capita CEBs and EBEs of unit value of export could be calculated combined with regional population and export data. These results are shown in Tables 3 and 4.

At national level, in 1997, 680.32 million tons of carbon were emitted that were caused by final use, and 159.20 million tons of carbon were generated by export, accounting for $81.04 \%$ and $18.96 \%$ of PBEs in China in 1997 respectively. By 2007, carbon emissions caused by the nation's final use increased to 1181.26 million tons, representing an increase of 73.63\% from 1997. Carbon emissions caused by export had also increased by 2007 to 445.39 million tons, an increase of $179.77 \%$ and significantly higher than the former increase rate. The implication here is that export expansion is one of the main reasons of carbon emissions increase in China.

\subsubsection{CBEs and regional difference}

At regional level, during 1997-2007, the domestic CBEs of every region increased. The North coastal region was the fastest increasing region (139.79\% increase), followed by the Middle region (92.17\%) and Beijing-Tianjin region (88.49\%), which all demonstrated a far higher CBEs increase than national average level (73.63\%). The slowest CBEs increase was found in the Northeast (21.93\%) owing to this region's slow GDP and household income growth.

Fig. 2 shows the relationship between regional CBEs and economic development in 1997 and 2007 respectively. It is can be seen that regions with higher per capita GDP, such as Beijing-Tianjin, East Coast, South Coast, generally had a higher per capita CBE, while a lower per capita GDP corresponded with a lower per capita CBEs. Therefore, per capita CBEs were positively proportional to regional economic development. From the data shown in Fig. 2, it can also be deduced that per capita CBEs of northern regions were generally higher than those of southern regions in China. This is partly related to heating habits in winter in northern areas, and rich hydropower in southern regions. In addition, although the regional differences in CBEs widened between 1997 and 2007 (the coefficient of variation of CBEs increased from

Table 3

Regional domestic CBEs in China.

\begin{tabular}{|c|c|c|c|c|c|c|c|c|}
\hline & \multicolumn{2}{|l|}{ CBEs } & \multicolumn{2}{|c|}{ PBEs (consumption) } & \multicolumn{2}{|c|}{ CBEs per capita } & \multicolumn{2}{|c|}{$\begin{array}{l}\text { Net outflow } \\
\text { (consumption) }\end{array}$} \\
\hline & \multicolumn{2}{|l|}{ MtC } & \multicolumn{2}{|l|}{ MtC } & \multicolumn{2}{|l|}{ tC } & \multicolumn{2}{|l|}{ MtC } \\
\hline & 1997 & 2007 & 1997 & 2007 & 1997 & 2007 & 1997 & 2007 \\
\hline NE & 111.23 & 135.63 & 111.63 & 144.59 & 1.058 & 1.250 & 0.40 & 8.96 \\
\hline JJ & 32.84 & 61.89 & 28.00 & 35.15 & 1.497 & 2.252 & -4.84 & -26.75 \\
\hline NC & 75.21 & 180.35 & 96.05 & 198.09 & 0.491 & 1.106 & 20.84 & 17.75 \\
\hline EC & 105.35 & 187.60 & 80.48 & 143.65 & 0.808 & 1.290 & -24.87 & -43.94 \\
\hline SC & 59.36 & 99.36 & 43.68 & 75.18 & 0.536 & 0.716 & -15.68 & -24.18 \\
\hline MR & 135.78 & 260.92 & 162.04 & 290.62 & 0.388 & 0.739 & 26.27 & 29.70 \\
\hline NW & 68.17 & 115.67 & 72.12 & 155.87 & 0.612 & 0.962 & 3.96 & 40.20 \\
\hline SW & 92.39 & 139.84 & 86.31 & 138.10 & 0.384 & 0.576 & -6.07 & -1.74 \\
\hline Nation & 680.32 & 1181.26 & 680.32 & 1181.26 & 0.556 & 0.909 & 0.00 & 0.00 \\
\hline Coefficient of variation & 0.385 & 0.416 & 0.485 & 0.519 & 0.536 & 0.476 & & \\
\hline
\end{tabular}

Source: author's own calculation. 
Table 4

Regional EBEs in China.

\begin{tabular}{|c|c|c|c|c|c|c|c|c|}
\hline & \multicolumn{2}{|l|}{ EBEs } & \multicolumn{2}{|c|}{ PBEs (export) } & \multicolumn{2}{|c|}{ EBEs of unit export } & \multicolumn{2}{|c|}{ Net outflow (export) } \\
\hline & \multicolumn{2}{|l|}{$\mathrm{MtC}$} & \multicolumn{2}{|l|}{$\mathrm{MtC}$} & \multicolumn{2}{|c|}{$\mathrm{tC} / 10^{3} \mathrm{CNY}$} & \multicolumn{2}{|l|}{$\mathrm{MtC}$} \\
\hline & 1997 & 2007 & 1997 & 2007 & 1997 & 2007 & 1997 & 2007 \\
\hline NE & 20.15 & 33.44 & 22.45 & 42.55 & 207.75 & 95.14 & 2.30 & 9.11 \\
\hline $\mathrm{JJ}$ & 12.79 & 27.66 & 10.76 & 17.16 & 127.70 & 47.04 & -2.03 & -10.50 \\
\hline $\mathrm{NC}$ & 13.42 & 61.92 & 20.75 & 74.74 & 130.30 & 79.65 & 7.33 & 12.82 \\
\hline EC & 45.12 & 156.69 & 33.20 & 101.55 & 100.45 & 48.53 & -11.92 & -55.14 \\
\hline SC & 47.79 & 104.86 & 29.16 & 61.00 & 84.37 & 36.42 & -18.62 & -43.86 \\
\hline MR & 8.85 & 30.46 & 23.93 & 73.74 & 175.75 & 87.08 & 15.08 & 43.28 \\
\hline NW & 5.62 & 16.89 & 9.27 & 43.86 & 185.85 & 105.02 & 3.65 & 26.98 \\
\hline SW & 5.48 & 13.48 & 9.68 & 30.79 & 147.36 & 73.25 & 4.20 & 17.31 \\
\hline Nation & 159.20 & 445.39 & 159.20 & 445.39 & 111.06 & 52.28 & 0.00 & 0.00 \\
\hline coefficient of variation & 0.858 & 0.907 & 0.460 & 0.491 & 0.294 & 0.349 & & \\
\hline
\end{tabular}

Source: author's own calculation. Data in this table are calculated at 1997 constant prices.

0.385 to 0.416 ), the coefficient of variation of per capita CBEs declined, suggesting that regional differences in per capita CBEs had narrowed.

\subsubsection{EBEs and regional difference}

Table 4 shows the regional EBEs of China. It is evident that the East Coastal and South Coastal regions were the main sources of EBEs, since they were the key export bases in China. The sum of the EBEs in these two areas accounted for $58.36 \%$ and $58.72 \%$ of national gross EBEs, while the total exports of these two regions accounted for $72.27 \%$ and $54.71 \%$ of the country in 1997 and 2007 respectively. However, the gross EBEs of the Middle and West regions (including MR, NW, SW) is low, accounting only for approximately $12-14 \%$ of the country's EBEs. By comparing the regional growth rates of EBEs with those of CBEs, it can be seen that the EBEs growth rates of each region were very fast and far higher than those of CBEs. The North Coastal region exhibited a leading growth rate at $361.38 \%$ from 1997 to 2007 . These datum show that, overall, there were large-scale carbon emissions created by the rapidly increasing regional export activity in China.

However, even though the East Coastal and South Coastal regions had the largest absolute values of EBEs, their embodied carbon emissions per unit of exported value were relatively lower than those of other regions (excepting the Beijing-Tianjin area), mainly owing to the high proportion of high value-added and high-tech commodity in their exports. In contrast, the carbon emissions embodied in the unit value of exported products of the Northwest, Northeast, North Coastal region and Middle region were higher, which indicated the presence of low value-added exports with high energy intensity, and high proportions of low-end manufacturing products. In addition, the results of the coefficients of variation shown in Table 4 highlight that regional differences in the value of EBEs and the EBEs per unit of export were both increasing. This reflected not only the scale of regional exports but also the export structure, within which there was a polarization trend; that is, regions with a "clean" export structure such as the South Coast and
East Coast were getting better, and regions with a "dirty" export structure such as the Middle and West regions were getting worse.

\subsection{Sectoral analysis}

Assuming that the production requirements for producing export or consumption in each sector are the same, emissions embodied in the consumptions and exports (demand) by sector as well as direct emissions (supply) for national consumption and export by sector in each region can be obtained. Thus, by subtracting "demand" from "supply", the sectoral components of regional net outflow emissions (figures in Tables 3 and 4) within China can be derived, see Fig. 3.

Fig. 3 shows that different sectors have different roles in the carbon emissions flow system. For example, the electricity and hot water supply sector is always the largest carbon "supplier" for consumption and export in each region. Sectors such as machinery, transport equipment, electric and electronics, food, textiles, and other services are all carbon "deposits" with different degrees of importance for consumption and export. For consumption (including capital formation), the dominant carbon "deposit" sectors are construction, other services, general and specialist machinery, food and textiles. For export, the main carbon "deposit" sectors are electric and electronics, textiles, and machinery. The major carbon deposit sectors driven by exports are almost all concentrated in the EC and SC regions, which induce significant unbalances between carbon "supplier" sectors and "deposit" sectors in those regions. Thus, EC and SC are the largest emissions inflow areas. When we focus on consumption (left side of Fig. 3), the carbon "supplier" sectors and "deposit" sectors for each region appear to be more balanced. Thus, this composition effect primarily explains why the net inflow of emissions in some regions is larger for exports than for consumption (e.g., EC, SC in 2007, see Tables 3 and 4), although most of the scales of sectoral components for consumption are larger than those for export (see Fig. 3).

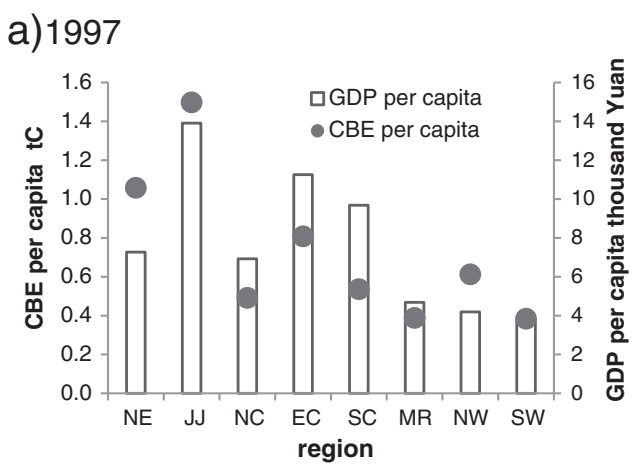

b) 2007

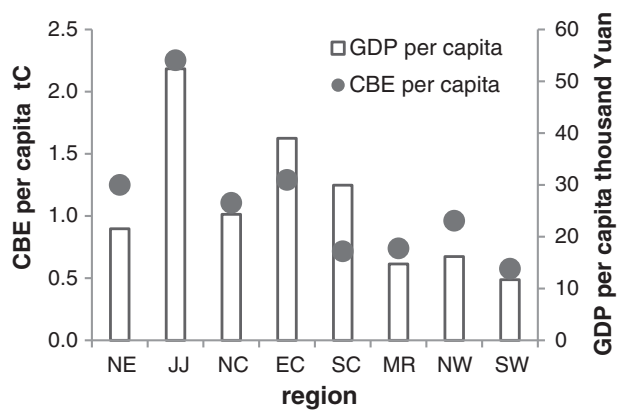




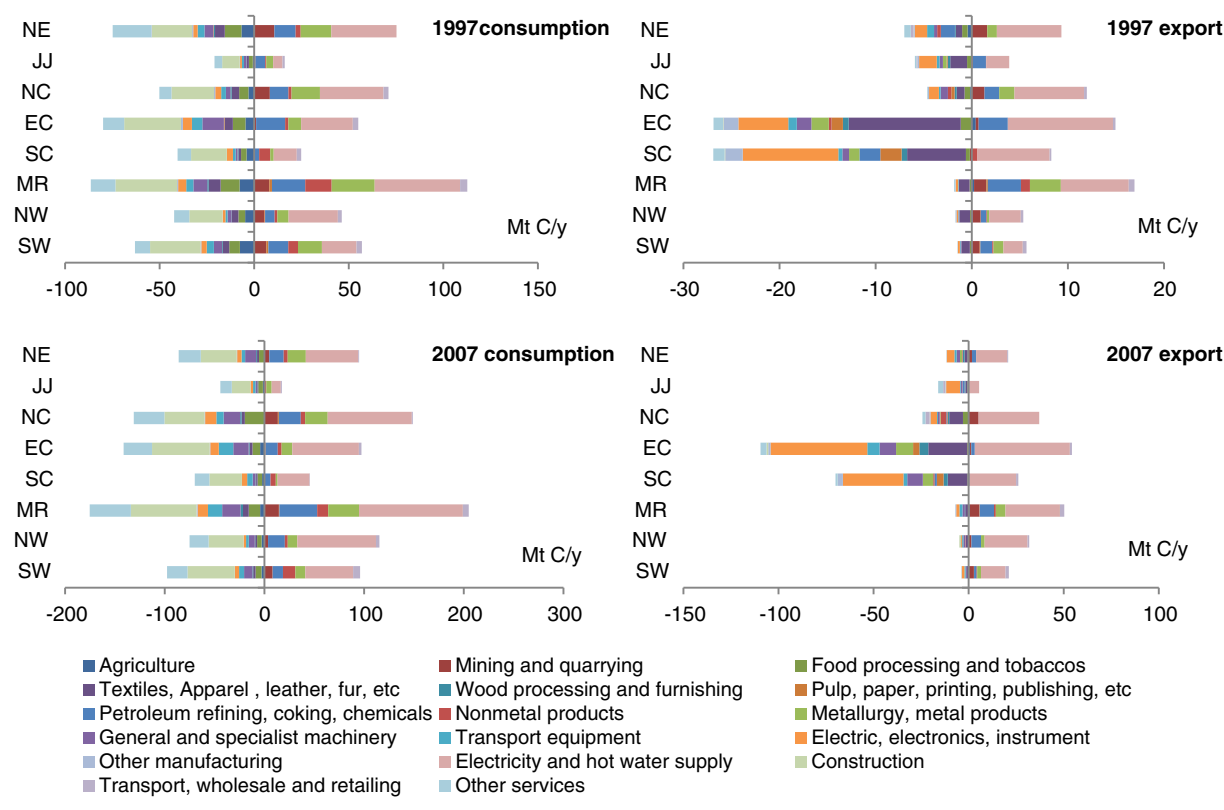

Fig. 3. Sectoral components of regional net outflow emissions within China for 1997 and 2007.

Several interesting changes from 1997 to 2007 are also evident in the outcomes in Fig. 3. First, the increase rates of "deposit" emissions embodied in the consumptions of transport equipment (142\% at the national level, similar hereafter in this paragraph), other services (140\%), machinery (134\%), and electric and electronics (113\%) are relatively faster than those of "deposit" emissions embodied in the consumptions of agriculture $(-55 \%)$, textiles ( $-30 \%)$, and food ( $43 \%)$. In some sectors such as agriculture and textiles, the increase rates are even negative. This law is more evident in developed regions in China, such as JJ, SC and EC. This change well corresponds with the changes in the regional consumption structure between 1997 and 2007. Second, for export, the outstanding sectoral mix changes of regional net outflow emissions embodied in demand-supply chains for export could be found on the right side of Fig. 3. In the one hand, emissions net inflow sectors are dominated by textiles and electric and electronics in 1997. In 2007, the electric and electronics sector grows to become the only dominant sector. In the other hand, emissions net outflow sectors are dominated by electricity supply, petroleum refining and chemicals as well as mining and quarrying in 1997. However in 2007, electricity supply becomes the only dominant outflow sector. These changes also reflect the changes in the energy structure in China.

\subsection{Carbon emissions embodied in the demand-supply chain}

\subsubsection{Carbon embodied in demand-supply chain driven by consumption (CEDSC)}

The net flow of emissions embodied in demand-supply chains driven by consumption increased rapidly from 51.46 million tons to 96.61 million tons in 1997-2007. At regional level, the main CEDSC net "export" regions included the Northwest, Middle region and North Coast, all of which experienced rapid increases in net "export" carbon. The Northwest increased the fastest (going from 3.96 million tons to 40.20 million tons) to become the largest net "export" carbon region by 2007, which was driven by supply increase of electricity, petroleum, coke and chemicals (Fig. 3).The East Coastal, South Coastal, and Beijing-Tianjin regions were the main CEDSC net "import" regions, all
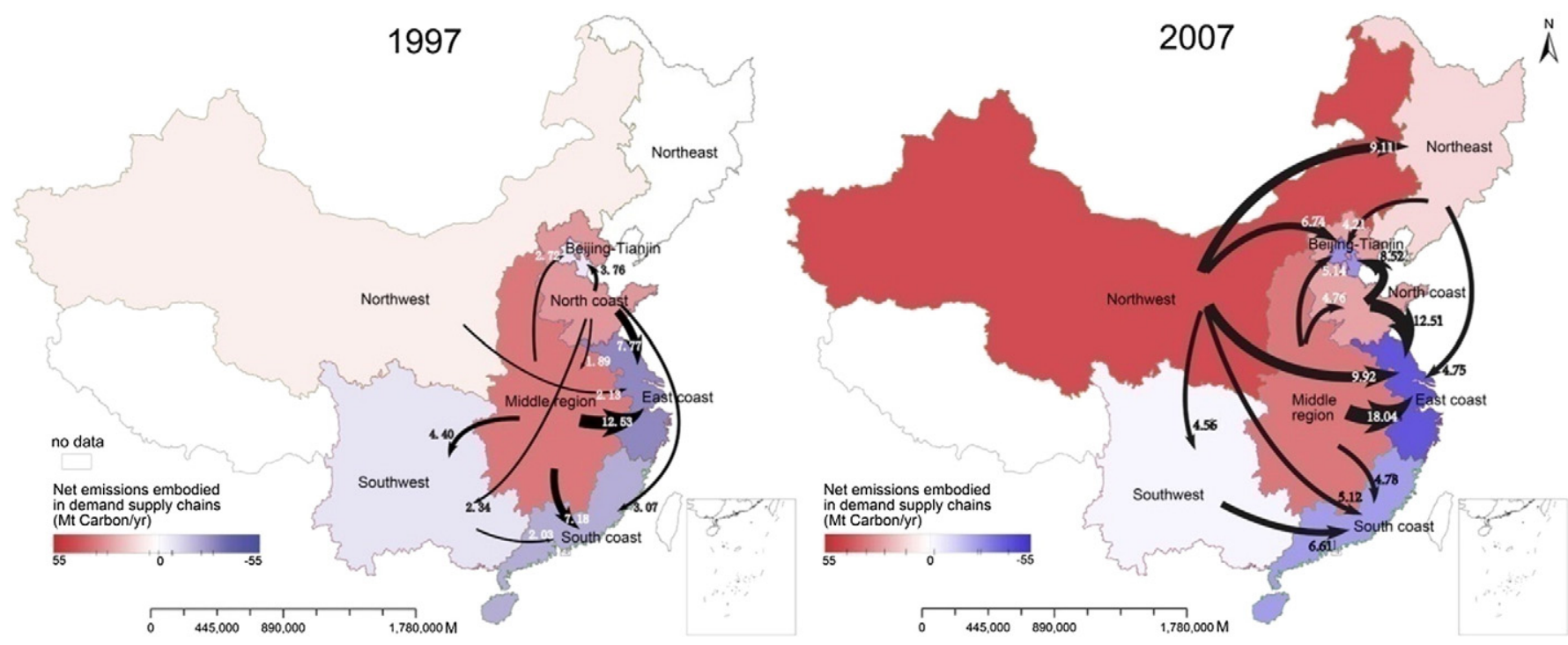

Fig. 4. Net carbon fluxes embodied in the demand-supply chain driven by domestic consumption in China. 

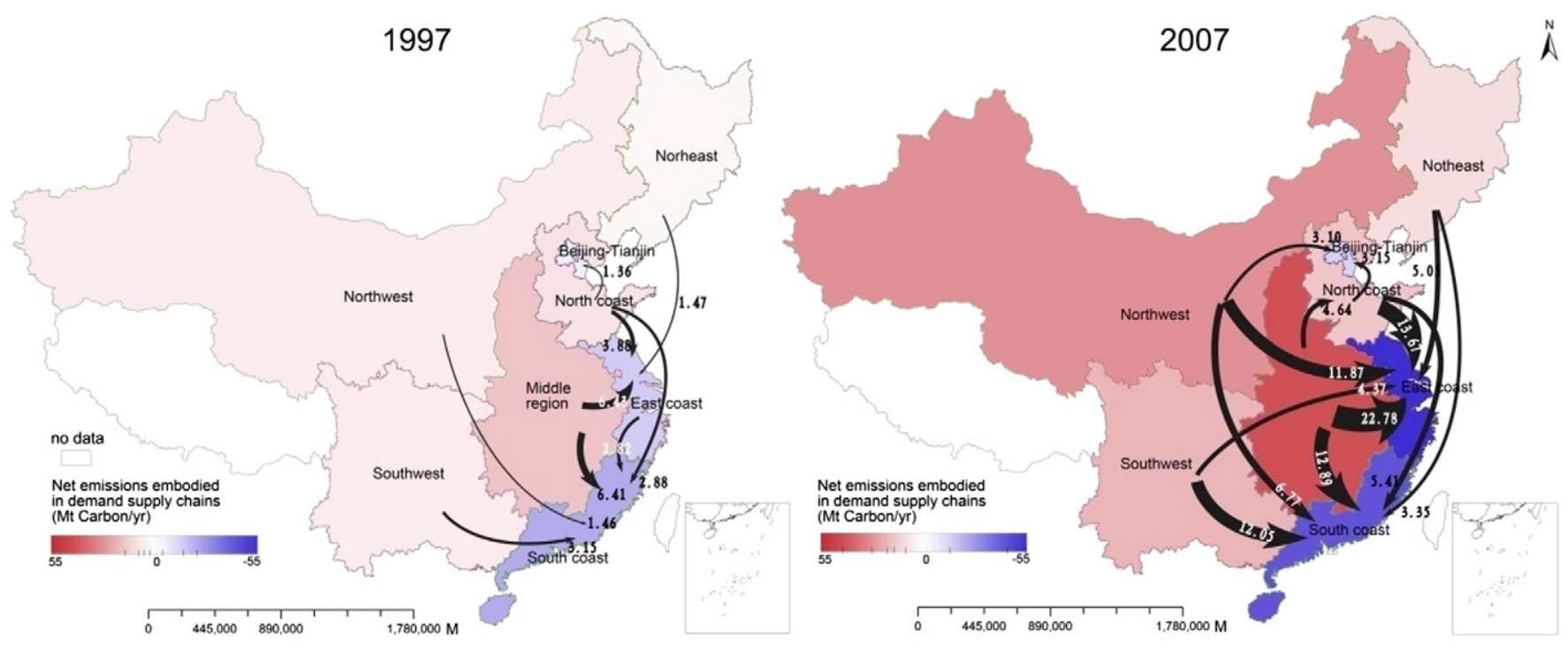

Fig. 5. Net carbon transfer embodied in demand-supply chain driven by export in China.

also undergoing rapid increases too. Beijing-Tianjin was the fastest growing region for importing carbon, showing a 4.52-fold increase within the decade. The Southwest was also a net "import" region, but its import was small and showed a decreasing trend.

Fig. 4 shows the spatial net flows of CEDSC in 1997 and 2007. The data showing that carbon emissions related to final consumption in affluent regions such as the East Coast, South Coast, and Beijing-Tianjin were partly outsourced to the North Coastal region and other poorer regions with abundant natural resources such as the Middle region, Northwest and Northeast. While this spatial flow pattern was not significantly altered, but the scales of flow dramatically expanded during 1997-2007, for example, the net flow scale from the Middle region to the East Coastal region increased from 12.53 million tons of carbon to 18.03 million tons, while the net flows from the Northwest to other regions were all also significantly segmented, making the Northwest the largest net "export" region in 2007.

There are two main factors informing the spatial flow pattern of CEDSC in China. The first relates to the geographical division of product activities. Generally, the net carbon "export" region is the producer and supplier of higher carbon intensity commodities such as electricity, minerals and chemicals, metal products, etc., while the net carbon "import" region is the producer and supplier of relatively lower carbon intensity commodities such as service, electrical and telecommunications equipment. In 1997, the energy and raw materials were still mainly produced in the Middle region and North Coast. By 2007, even though the Middle region and North Coastal region were still key suppliers, the implementation of the western development strategy meant that the Northwest quickly became the largest energy and raw materials production base. Most of the energy and raw materials needed in the southeast coast and Beijing-Tianjin areas for manufacturing currently need to be delivered from the Northwest region.

The second factor affecting the spatial flow trend of CEDSC in China is the high level of variation in regional consumption markets. The population and density in the eastern part of China are much higher than that in other areas. Since the reform and opening-up, the east region has been economically advanced. This causes capital and population continue to be attracted and further concentrated in east region which, in turn, has lent itself to a larger consumption market, especially the durable consumption market that inevitably follows a developed economy. Thus the Southeast coast and Beijing-Tianjin areas are the primary importers of carbon embodied in the demand-supply chain triggered by final consumption.

\subsubsection{Embodied carbon in the demand-supply chain driven by export (CEDSE)}

During 1997-2007, there was no big change in the spatial flow pattern of the inter-regional net transfer of embodied carbon in the demand-supply chain driven by export, which was mainly flowing from the North Coastal, Middle and West regions to areas of the Southeast Coastal and Beijing-Tianjin regions. However, the scale of these fluxes experienced substantial increase, especially the flows from the Middle and West regions to the Southeast Coastal region, which exhibited leading increase rates (Fig. 5). For example, driven by export, the amount of net carbon emissions transferred from the Middle region to the East Coastal region expanded from 6.43 million tons to 22.78 million tons during 1997-2007, and the net carbon that flowed from the Northwest to the East Coastal region caused by export increased from 1.42 to 11.87 million tons-a 8.35-fold increase. Therefore, it can be argued that the expansion of export activities in the Southeast Coastal region led to a substantial increase of carbon emissions in the Middle and West regions.

The main reason for this rapid increase of carbon transfer embodied in the demand-supply chain driven by export was the quick expansion and sustained concentration of export activity in China. Between 1997 and 2007, the absolute value of China's total export increased from 1516.07 billion CNY to 8331.57 billion CNY (at 1997 constant prices $^{3}$ ) -5.50 -fold in a decade-with the East Coastal and South Coastal regions being the primary export bases. The massive inter-regional transfer of carbon emissions caused by exports also showed that, although most of the export activities occurred in the Southeast coastal areas on the surface, in reality the Middle and West regions played an important role in supplying energy and raw material in the export commodities production chain.

\section{Discussion}

This section compares the results of this study with that from previous studies. $\mathrm{CO}_{2}$ emissions embodied in demand-supply chains in 2007 in the studies of Feng et al. (2013) and Meng et al. (2013), which both adopt the same region classification and the same method, are compared. For comparison, carbon emissions that are measured in carbon in the present paper are transferred to $\mathrm{CO}_{2}$ by multiplying the number

\footnotetext{
${ }^{3}$ The 1997 constant price of 2007 is calculated based on the producer price indexes (PPIs) during 1997-2007.
} 
Table 5

Comparison with previous estimates of the gross emissions embodied in demand-supply chains in China for 2007 ( $\left.\mathrm{Mt} \mathrm{CO}_{2} / \mathrm{yr}\right)$.

\begin{tabular}{|c|c|c|c|c|c|c|c|c|c|}
\hline & & NE & $\mathrm{JJ}$ & NC & $\mathrm{EC}$ & SC & MR & NW & SW \\
\hline \multirow[t]{8}{*}{ Feng et al. (2013) (top 10 fluxes of emissions embodied in trade) } & $\mathrm{NE}$ & & & & & & & & \\
\hline & $\mathrm{JJ}$ & & & & & & & & \\
\hline & $\mathrm{NC}$ & 78 & 100 & & 214 & & 83 & & \\
\hline & $\mathrm{EC}$ & & & & & & & & \\
\hline & SC & & & & & & & & \\
\hline & MR & & & 118 & 248 & 115 & & & \\
\hline & NW & 91 & & & 119 & & & & \\
\hline & SW & & & & & 124 & & & \\
\hline \multirow{8}{*}{ Meng et al. (2013) (inter-regional spillover of carbon emissions) } & $\mathrm{NE}$ & & 26.53 & 66.05 & 47.44 & 25.28 & 78.88 & 19.00 & 24.92 \\
\hline & $\mathrm{JJ}$ & 7.45 & & 39.76 & 10.94 & 5.68 & 15.85 & 5.34 & 6.30 \\
\hline & $\mathrm{NC}$ & 31.15 & 54.53 & & 69.33 & 34.50 & 114.91 & 31.20 & 33.52 \\
\hline & $\mathrm{EC}$ & 6.79 & 4.77 & 19.32 & & 29.71 & 60.15 & 9.79 & 14.94 \\
\hline & SC & 11.66 & 4.95 & 14.94 & 29.80 & & 45.39 & 14.76 & 42.22 \\
\hline & MR & 19.84 & 17.52 & 89.66 & 157.13 & 49.90 & & 27.98 & 35.27 \\
\hline & NW & 25.00 & 20.00 & 71.56 & 75.33 & 41.46 & 101.90 & & 49.42 \\
\hline & SW & 16.95 & 7.7 & 26.65 & 41.74 & 32.47 & 69.61 & 29.18 & \\
\hline \multirow[t]{8}{*}{ This present paper (emissions embodied in demand-supply chains) } & $\mathrm{NE}$ & & 29.31 & 60.93 & 54.24 & 26.80 & 35.91 & 20.12 & 16.52 \\
\hline & $\mathrm{JJ}$ & 7.21 & & 8.51 & 17.46 & 8.31 & 9.54 & 6.46 & 6.81 \\
\hline & $\mathrm{NC}$ & 49.06 & 51.33 & & 132.88 & 42.82 & 61.04 & 38.66 & 26.88 \\
\hline & $\mathrm{EC}$ & 18.29 & 19.44 & 36.87 & & 50.97 & 51.52 & 22.68 & 22.14 \\
\hline & SC & 4.96 & 7.19 & 8.62 & 35.40 & & 33.30 & 7.97 & 22.07 \\
\hline & MR & 30.07 & 37.68 & 95.52 & 201.20 & 98.07 & & 49.40 & 42.65 \\
\hline & NW & 61.26 & 42.52 & 62.72 & 102.57 & 51.53 & 53.20 & & 31.80 \\
\hline & SW & 6.71 & 13.39 & 17.43 & 41.46 & 90.47 & 42.51 & 13.99 & \\
\hline
\end{tabular}

by $44 / 12$ to correspond with that in other studies. The results of Feng et al. (2013) were obtained from Fig. 1 in their paper, and only the top 10 largest fluxes of emissions were obtained. The results are shown in Table 5.

Table 5 shows that the results in this paper are somewhere in the middle of the estimations of Feng et al. (2013) and Meng et al. (2013). For example, the largest inter-regional emissions flux values are all from MR to EC in three studies, but the value of the present paper (201.2 Mt) is smaller than that of Feng et al. (248 Mt) and larger than that of Meng et al. (157.1 Mt). This conclusion similarly holds for the fluxes of $\mathrm{NC} \rightarrow \mathrm{EC}, \mathrm{MR} \rightarrow \mathrm{NC}, \mathrm{NW} \rightarrow \mathrm{EC}$, and so on.

Su and Ang (2014) state that the estimate of embodiments in international exports can be significantly affected by the choice of either the EEBT or the MRIO approach for interregional trade because of interregional feedback effects (Su and Ang, 2011). Zhang et al. (2014) demonstrate that this conclusion likewise holds for interregional trade. The current study finds that the estimate of embodied emissions can also be affected by the concept of "embodied" and data sources even though the method is similar. Most studies have estimated the emissions embodied in trade (e.g. Feng et al. (2013) and Zhang et al. (2014)). However, the concept of emissions embodied in demandsupply chains promoted by this study differs from that of emissions embodied in trade because of the effect of interregional feedback. Su and Ang (2011) illustrate clearly how the emissions embodied in exports are absorbed in the infinite rounds. In other words, the emissions in exports to intermediate use are reallocated to those associated with the final demand. Generally, emissions embodied in trade would be greater than emissions embodied in demand-supply chains because emissions embodied in entrepot trade offset part of the emissions embodied in gross trade. Therefore, the estimated results of Feng et al. (2013) are greater than those in this paper. Another reason why emissions flows reported by Feng et al. (2013) might be higher is the inclusion of emissions embodied in international imports. In fact, the meaning of "emissions embodied in the demand-supply chain" in this paper is similar to that of "spillover of carbon emissions" promoted by Meng et al. (2013), but the results suggest some differences as well. These differences may be attributed to other factors such as data sources. The MRIO tables in the study of Meng et al. (2013) are compiled by the China State Information Center (Zhang and Qi, 2012). This study adopts the data from the National Statistics Bureau (Liu et al., 2012).
Moreover, we admit that both sectoral aggregation and spatial aggregation would influence the calculation results of emissions embodied in the demand-supply chains (Su and Ang, 2010; Su et al., 2010). Generally, a more disaggregated detailed sectors and spaces yield more accurate results. Restricted by the sectoral and spatial aggregation of the 1997 CMRIO (with 17 sectors and 8 regions, which we think is authoritative and which is available publicly), this paper only estimates the change of embodied emission between 1997 and 2007 at a relatively smaller aggregation level $(17 \times 8)$. In order to explain the effect of sectoral and spatial aggregation on embodied emissions, we recalculate the emissions embodied in demand-supply chains in 2007 at the aggregation level of 30 sectors and 30 regions in China based on the original national energy consumption data from the Chinese National Bureau of Statistics and the original 2007 CMRIO $(30 \times 30)$, and then the results are aggregated into 8 regions according to previous regional divisions to facilitate comparison with the results at the aggregation level of $17 \times 8$. Table 6 displays the comparison of regional net flow out emissions between the two sets of aggregation levels. Table 6 shows that aggregation level is a major factor that influences the results of the embodied emissions. This influence mainly comes from the sectoral and spatial differences of energy consumption, interregional trade, and consumption level. Additional sectoral and spatial differences indicate results that are more varied after sectoral or spatial aggregation. Using more detailed aggregation-level data or choosing sectors or regions with similar economic characteristics to

Table 6

Comparison of regional net flow out emissions in China in 2007 between two sets of aggregation level $\left(\mathrm{Mt} \mathrm{CO}_{2} / \mathrm{yr}\right)$.

\begin{tabular}{|c|c|c|c|c|}
\hline \multirow[t]{2}{*}{ Region } & \multicolumn{2}{|c|}{$\begin{array}{l}\text { Net flow out } \\
\text { (consumption) }\end{array}$} & \multicolumn{2}{|c|}{ Net flow out (export) } \\
\hline & $8 * 17$ & $30 * 30$ & $8 * 17$ & $30 * 30$ \\
\hline $\mathrm{NE}$ & 8.96 & 6.26 & 9.11 & 8.30 \\
\hline $\mathrm{JJ}$ & -26.75 & -31.27 & -10.50 & -9.34 \\
\hline $\mathrm{NC}$ & 17.75 & 25.59 & 12.82 & 9.95 \\
\hline $\mathrm{EC}$ & -43.94 & -52.36 & -55.14 & -47.15 \\
\hline SC & -24.18 & -22.83 & -43.86 & -39.01 \\
\hline MR & 29.70 & 30.69 & 43.28 & 37.08 \\
\hline NW & 40.20 & 46.04 & 26.98 & 23.14 \\
\hline SW & -1.74 & -2.13 & 17.31 & 17.02 \\
\hline
\end{tabular}


aggregate both could diminish the variation in the results. This aspect is the future research direction of our study.

\section{Conclusions}

Based on the MRIO, CBEs and EBEs are distinguished, and method to calculate carbon emissions embodied in the demand-supply chains for consumption and export for one country is set up. Taking China as an example, based on MRIO tables for 1997 and 2007, CBEs, EBEs, CEDSC and CEDSE at the sub-national level were analyzed respectively. The following main findings and policy implications were reached:

(1) The PBEs (reflecting the territorial direct carbon emissions) of each region experienced a rapid increase in 1997-2007, with the fastest growing area being the Northwest. Since the implementation of the western development strategy, Inner Mongolia, Shaanxi and other provinces in the Northwest region of China have gradually become important energy supplying bases. At the same time, the Northwest region of China has remained the area with the lowest energy efficiency and highest energy consumption per unit of output. Large-scale energy exploration in these areas may have brought them a significant amount of revenue and rapid urban development, but may have also created challenges such as ecological damage, a single industrial structure, slow resident income growth, and so forth. Therefore, in the Northwest Territories, while extracting energy and other resources, local government should pay attention to policies that help to avoid ecological damage such as that experienced in traditional energy-intensive areas. These policies should also focus on how to extend the industrial chain based on energy extraction in order to achieve continuous development, how to increase employment and improve household incomes, and how to improve the technology level and efficiency of the use of energy resources.

In addition, it was found that the regional direct carbon emission factor is inversely proportional to regional economic development. That is, developed regions generally have a better industrial structure and higher energy-use technology, as well as low carbon emissions level per unit of output. Conversely, regions with a low level of economic development generally contain low-level manufacturing industry, with a larger proportion of energy and raw materials industries, and lower energy-use technology, with consequently higher carbon emissions per unit of output. The expansion of regional differences in direct carbon emissions factors, along with of the increasing gap between regional per capita GDP in 1997-2007, also prove above conclusion. The expansion of regional differences in carbon emissions is not only harmful to the implementation of regional carbon emission reduction policies, but is also not conducive to the sustainable development of the regional economies. Therefore, narrowing regional gaps between economic growth and carbon emissions by accelerating industrial development and improving energy utilization technology in less developed areas with abundant fossil fuels is an urgent challenge for central government to resolve.

(2) CBEs and EBEs refer to the full emissions caused by final consumption and export respectively. Transferred carbon emissions embodied in demand-supply chains involved in consumption and export reflect where carbon dioxide caused by final use activities emits. This can then reveal the spatial mismatch between beneficiaries and victims of environment pollution. From the results pertaining to $\mathrm{CBEs}$ and EBEs, three key implications emerged.

First, along with the improvement of Chinese people's consumption level, carbon emissions caused by final consumption showed a significant increase. In addition, per capita CBEs were positively proportional to per capita GDP, meaning that carbon emissions caused by per capita consumption increased in line with the improvement of the economic development level. This, in turn, partly reflects that economic growth did not make people's consumption patterns change toward ecological solutions but, rather, expanded existing consumption patterns, or the change in the consumption towards "greener" pattern could have been offset by a shift of production to "dirtier" regions with low technology and high emissions intensity. Thus, promoting eco-consumption patterns and educating consumers about making ecological choices as well as promoting production technology and energy efficiency in industrial transfer in regions can be seen as key tasks in constructing an ecological Chinese civilization. ${ }^{4}$

Second, as China became more deeply involved in the global production chain, carbon emissions caused by expanding exports also greatly increased. While it seemed that EBEs mostly occurred in the Southeast coastal areas, in reality there were significant carbon emissions "imported" from Middle West areas. Therefore, further adjusting the export structure, increasing the technological content and added value of export commodities, limiting exports of high energy intensity and low-end products could help to reduce carbon emissions in South east coastal areas as well as in the Middle and West regions.

Third, the inter-regional net transferred carbon emissions embodied in demand-supply chains caused by final consumption and exports had both increased greatly. The primary transfer directions were both from poorer regions such as Northwest, North coastal and Middle regions to developed regions such as Beijing-Tianjin, East coastal and South coastal regions. The region that experienced the most significant change in 1997-2007 was the Northwest, whether it was a case of net transferred carbon emissions caused by final consumption or that caused by exports, the Northwest was the leading region in terms of carbon emissions net outflow. Therefore, from the perspective of consumption, it can be argued that less developed areas with abundant natural resources such as the Northwest are in disadvantaged position as they need to destroy their own environment in order to meet consumer demand in developed regions, while developed regions do not need to pay an equivalent cost. To solve this problem, several scholars have proposed the concept of ecological compensation ${ }^{5}$ (Marie et al., 2013; Villarroya and Puig, 2010; Zheng and Zhang, 2006). This has also been presented in official documents from Chinese central government as a means of resolving the financial problems associated with ecological restoration ${ }^{6}$. However, this has been seen as problematic owing to the most critical issue in ecological compensation-the quantitative accounting of inter-regional ecological impact. From the data in this study, it can be argued that the promotion of the CBEs concept, at least in the field of carbon compensation, provides a quantitative way of measuring inter-regional ecological impact, and thus a valuable reference for the scientific measurement of ecological compensation in other fields.

In conclusion, with China's increasing participation in global production chains and constant economic development, the country's interregional economic ties have grown closer. Transferred carbon emissions embodied in regional demand-supply chains, however, have rapidly expanded. This study has revealed that the absolute values of interregional net transferred carbon emissions embodied in demand-supply chains during 1997-2007 were large and showed a rapid growing trend. It was also found that less developed regions with abundant fossil fuels tend to be a net outflow of carbon emissions. Considering these factors, it can be said that the embodied net transfer of carbon emissions caused by final consumption and exports had increased significantly. This

\footnotetext{
${ }^{4}$ The 17th National Congress of Communist Party of China clearly points out that China will develop an ecological civilization.

${ }^{5}$ An environmental protection policy intended to make sure the regions and industries that benefit most from the exploitation of natural resources pay for the damages caused to the environment

${ }^{6}$ Ecological compensation was elaborated in the Report to the Eighteenth National Congress of the Communist Party of China.
} 
paper recommends that government policies should be pursued that promote the economic development of less developed regions, improve consumer attitudes towards ecological consumption, and implement an ecological compensation system, in order to reduce overall carbon emissions in China.

Several potential extensions of this study must be accomplished in the future. The main purpose of this study is to measure carbon emissions embodied in domestic demand-supply chains within China. We did not estimate CBEs including import for consumption. Thus, we need more supported data, such as IO tables and energy use in other countries. Most analyses in this paper are discussed at the aggregated regional and sectoral levels due to the data limitations. Therefore, future studies are expected to estimate emissions flows embodied in interprovincial demand-supply chains at a more detailed sectoral level. Additionally, other resources and pollutions, (i.e., water, sulfur dioxide, and nitrogen dioxide) that are embodied in regional demand-supply chains in China are worthy of future investigation.

\section{Acknowledgments}

We wish to acknowledge the helpful funding from the National Natural Science Foundation of China (Grant nos. 41101118, 71233004 and 41125005) and National Basic Research Program of China (973 Program, Grant no. 2012CB95570002).

\section{Appendix A}

\section{Table A1}

Industrial classification.

\begin{tabular}{lll}
\hline No. & Industries & Code in GB/T 4754-2002 \\
\hline 1 & Agriculture & $01-05$ \\
2 & Mining and quarrying & $06-11$ \\
3 & Food processing and tobaccos & $13-16$ \\
4 & Textiles, apparel, leather, fur, etc. & $17-19$ \\
5 & Wood processing and furnishing & $20-21$ \\
6 & Pulp, paper, printing, publishing, etc & $22-24$ \\
7 & Petroleum refining, coking, chemicals & $25-30$ \\
8 & Nonmetal products & 31 \\
9 & Metallurgy, metal products & $32-34$ \\
10 & General and specialist machinery & $35-36$ \\
11 & Transport equipment & 37 \\
12 & Electric, electronics, instrument & $39-41$ \\
13 & Other manufacturing & $42-43$ \\
14 & Electricity and hot water supply & $44-46$ \\
15 & Construction & $47-50$ \\
16 & Transport, wholesale and retailing & $51-59,63,65$ \\
17 & Other services & $60-62,66-98$ \\
\hline
\end{tabular}

\section{References}

Afton, C.S., Qu, J.S., Wang, Q., 2011. Carbon inequality at the sub-national scale: a case study of provincial-level inequality in $\mathrm{CO}_{2}$ emissions in China 1997-2007. Energy Policy 39 (9), 5420-5428.

Ahmad, N., Wyckoff, A., 2003. Carbon Dioxide Emissions Embodied in International Trade of Goods. OECD Science, Technology and Industry Working Papers 15. OECD Publishing.

Barrett, J., Peters, G., Wiedmann, T., et al., 2013. Consumption-based GHG emission accounting: a UK case study. Clim. Pol. 13 (4), 451-470.

Bednar-Friedl, B., Schinko, T., Steininger, K.W., 2012. The relevance of process emissions for carbon leakage: a comparison of unilateral climate policy options with and without border carbon adjustment. Energy Econ. 34 (Supplement 2), S168-S180.

Chen, Z.M., Chen, G.Q., 2011. An overview of energy consumption of the globalized world economy. Energy Policy 39 (10), 5920-5928.

Chen, G.Q., Zhang, B., 2010. Greenhouse gas emissions in China 2007: inventory and input-output analysis. Energy Policy 38 (10), 6180-6193.

Davis, S.J., Caldeira, K., 2010. Consumption-based accounting of CO2 emissions. Proc. Natl. Acad. Sci. U. S. A. 107 (12), 5687-5692.

Davis, S.J., Peters, G.P., Caldeira, K., 2011. The supply chain of $\mathrm{CO}_{2}$ emissions. Proc. Natl. Acad. Sci. U. S. A. 108 (45), 18554-18559.

Dietzenbacher, E., Pei, J., Yang, C., 2012. Trade, production fragmentation, and China's carbon dioxide emissions. J. Environ. Econ. Manag. 64 (1), 88-101.
Dong, Y., Ishikawa, M., Liu, X., Wang, C., 2010. An analysis of the driving forces of CO2 emissions embodied in Japan-China trade. Energy Policy 38 (11), 6784-6792.

Du, H., Guo, J., Mao, G., et al., 2011. CO2 emissions embodied in China-US trade: inputoutput analysis based on the energy/dollar ratio. Energy Policy 39 (10), 5980-5987.

Fan, Y., Liang, Q.M., Wei, Y.M., et al., 2007. A model for China's energy requirements and CO2 emissions analysis. Environ. Model Softw. 22, 378-393.

Feng, K., Hubacek, K., Guan, D., 2009. Lifestyles, technology and CO2 emissions in China: a regional comparative analysis. Ecol. Econ. 69 (1), 145-154.

Feng, K., Davis, S.J., Sun, L., et al., 2013. Outsourcing CO2 within China. Proc. Natl. Acad. Sci. U. S. A. 110 (28), 1-6.

Guan, D., Peters, G.P., Weber, C.L., Hubacek, K., 2009. Journey to world top emitter: an analysis of the driving forces of China's recent $\mathrm{CO} 2$ emissions surge. Geophys. Res. Lett. 36, 1-5.

Guo, J., Zhang, Z., Meng, L., 2012. China's provincial CO2 emissions embodied in international and interprovincial trade. Energy Policy 42, 486-497.

IPCC, 2006. IPCC Guidelines for national greenhouse gas inventories. In: Eggleston, H.S. Buendia, L., Miwa, K., Ngara, T., Tanabe, K. (Eds.), Prepared by the national greenhouse gas inventories programme. IGES, Japan, pp. 123-126.

Lenzen, M., 1998. Primary energy and greenhouse gases embodied in Australian final consumption-an input-output analysis. Energy Policy 26 (6), 495-506.

Lenzen, M., Pade, L.L., Munksgaard, J., 2004. CO2 multipliers in multi-region input-output models. Econ. Syst. Res. 16 (4), 391-412.

Leontief, W., Strout, A., 1963. Multi-regional Input-Output Analysis. In: Barna, T. (Ed.) Structural Interdependence and Economic Development. St. Martin's Press, New York

Li, Y., Hewitt, C.N., 2008. The effect of trade between China and the UK on national and global carbon dioxide emissions. Energy Policy 36 (6), 1907-1914.

Lin, B.Q., Sun, C.W., 2010. Evaluating carbon dioxide emissions in international trade of China. Energy Policy 38 (1), 613-621.

Liu, W.D., Chen, J., Tang, Z.P., et al., 2012. 2007 China Inter-Province Input-Output Table: Theory and Practice. China Statistics Press (in Chinese).

Liu, H., Liu, W., Fan, X., Liu, Z., 2015. Carbon emissions embodied in value added chains in China. Journal of Cleaner Production 103, 362-370.

Machado, G., Schaeffer, R., Worrell, E., 2001. Energy and carbon embodied in the international trade of Brazil: an input-output approach. Ecol. Econ. 39 (3), 409-424.

Mäenpää, I., Siikavirta, H., 2007. Greenhouse gases embodied in the international trade and final consumption of Finland: an input-output analysis. Energy Policy 35 (1), $128-143$.

Marie, A.B., Bruce, D.C., Barry, J.B., et al., 2013. Ecological compensation: an evaluation of regulatory compliance in New Zealand. Impact Assess. Proj. Apprais. 31 (1), 34-44.

Mcgregor, P.G., Swales, J.K., Turner, K., 2008. The CO2 "trade balance" between Scotland and the rest of the UK: performing a multi-region environmental input-output analysis with limited data. Ecol. Econ. 66 (4), 662-673.

Meng, L., Guo, J., Chai, J., Zhang, Z., 2011. China's regional $\mathrm{CO}_{2}$ emissions: characteristics, inter-regional transfer and emission reduction policies. Energy Policy 39 (10), 6136-6144.

Meng, B., Xue, J., Feng, K., Guan, D., Fu, X., 2013. China's inter-regional spillover of carbon emissions and domestic supply chains. Energy Policy 61, 1305-1321.

Munksgaard, J., Pedersen, K.A., 2001. CO2 accounts for open economies: producer or consumer responsibility? Energy Policy 29 (4), 327-334.

Munksgaard, J., Pade, L.L., Minx, J., Lenzen, M., 2005. Influence of trade on national $\mathrm{CO}_{2}$ emissions. Int. J. Glob. Energy Issues 23 (4), 324-336.

Pan, J., Phillips, J., Chen, Y., 2008. China's balance of emissions embodied in trade: approaches to measurement and allocating international responsibility. Oxford Review of Economic Policy 24 (2), 354-376.

Peters, G.P., 2008. From production-based to consumption-based national emissions inventories. Ecol. Econ. 65 (1), 13-23.

Peters, G.P., Hertwich, E.G., 2008. Post-Kyoto greenhouse gas inventories: Production versus consumption. Climatic Change 86 (1-2), 51-66.

Peters, G.P., Weber, C.L., Guan, D., Hubacek, K., 2007. China's growing $\mathrm{CO}_{2}$ emissions-a race between increasing consumption and efficiency gains. Environ. Sci. Technol. 41 (17), 5939-5944.

Peters, G.P., Minx, J.C., Weber, C.L., Edenhofer, O., 2011. Growth in emission transfers via international trade from 1990 to 2008. Proc. Natl. Acad. Sci. 108 (21), 8903-8908.

Rhee, H.C., Chung, H.S., 2006. Change in $\mathrm{CO}_{2}$ emission and its transmissions between Korea and Japan using international input-output analysis. Ecol. Econ. 58 (4), $788-800$.

Sánchez-Chóliz, J., Duarte, R., 2004. $\mathrm{CO}_{2}$ emissions embodied in international trade: evidence for Spain. Energy Policy 32 (18), 1999-2005.

Shi, M., Wang, Y., Zhang, Z., Zhou, X., 2012. Regional carbon footprint and interregional transfer of carbon in China. Acta Geograph. Sin. 67 (10), 1327-1338.

State Information Center of China, 2005. Multi-Regional Input-Output Model for China Social Sciences Academic Press (in Chinese).

Su, B., Ang, B.W., 2010. Input-output analysis of $\mathrm{CO} 2$ emissions embodied in trade: the effects of spatial aggregation. Ecol. Econ. 70 (1), 10-18.

$\mathrm{Su}$, B., Ang, B.W., 2011. Multi-region input-output analysis of $\mathrm{CO}_{2}$ emissions embodied in trade: the feedback effects. Ecol. Econ. 71, 42-53.

$\mathrm{Su}, \mathrm{B} .$, Ang, B.W., 2013. Input-output analysis of $\mathrm{CO}_{2}$ emissions embodied in trade: competitive versus non-competitive imports. Energy Policy 56, 83-87.

Su, B., Ang, B.W., 2014. Input-output analysis of $\mathrm{CO}_{2}$ emissions embodied in trade: a multi-region model for China. Appl. Energy 114, 377-384.

Su, B., Huang, H., Ang, B., Zhou, P., 2010. Input-output analysis of CO2 emissions embodied in trade: the effects of sector aggregation. Energy Econ. 32 (1), 166-175.

$\mathrm{Su}, \mathrm{B}$., Ang, B., Low, M., 2013. Input-output analysis of $\mathrm{CO}_{2}$ emissions embodied in trade and the driving forces: processing and normal exports. Ecol. Econ. 88, 119-125.

Villarroya, A., Puig, J., 2010. Ecological compensation and environmental impact assessment in Spain. Environ. Impact Assess. Rev. 30 (6), 357-362. 
Weitzel, M., Ma, T., 2014. Emissions embodied in Chinese exports taking into account the special export structure of China. Energy Econ. 45, 45-52.

Wilting, H., Vringer, K., 2007. Environmental accounting from a producer or a consumer principle: an empirical examination covering the world. 16th International InputOutput Conference. Istanbul, Turkey.

Xu, M., Allenby, B., Chen, W.Q., 2009. Energy and air emissions embodied in China-U.S Trade: eastbound assessment using adjusted bilateral trade data. Environ. Sci. Technol. 43 (9), 3378-3384.

Yang, Z., et al., 2014. Constructing long-term (1948-2011) consumption-based emissions inventories. J. Clean. Prod. http://dx.doi.org/10.1016/j.jclepro.2014.03.053.

Yu, H.C. Wang, L.M., 2010. Carbon emission transfer by international trade: taking the case of Sino-U.S. merchandise trade as an example. J. Resour. Ecol. 1 (2), 155-163.

Zhang, Y., 2012. Scale, technique and composition effects in trade related carbon emissions in China. Environ. Resour. Econ. 51 (3), 371-389.
Zhang, Y., 2013. The responsibility for carbon emissions and carbon efficiency at the sectoral level: evidence from China. Energy Econ. 40 (11), 967-975.

Zhang, Y., Qi, S., 2012. China's Interregional Input-Output Tables for 2002 and 2007. China Statistics Press, Chinese.

Zhang, Z., Guo, J., Hewings, G.J.D., 2014. The effects of direct trade within China on regional and national $\mathrm{CO}_{2}$ emissions. Energy Econ. 46, 161-175.

Zheng, H.X., Zhang, L.B., 2006. Chinese Practices of Ecological Compensation and Payments for Ecological and Environmental Services and its Policies in River Basins, Submitted to the World Bank.

Zsófia, V.M., 2013. A consumption-based approach to carbon emission accounting-sectoral differences and environmental benefits. J. Clean. Prod. 42, 83-95. 